\title{
Recent patent applications in RNA interference
}

\begin{tabular}{|c|c|}
\hline Patent number & Description \\
\hline US 20090013433 & $\begin{array}{l}\text { A transgenic plant comprising a brassinosteroid receptor } \\
\text { BRI1 kinase inhibitor } 1 \text { (BKI1)-type polypeptide or modulator } \\
\text { of bki1-type gene expression; useful for displaying modulated } \\
\text { brassinosteroid response and plant phenotype. The modulator } \\
\text { in the transgenic plant is an RNA interference or antisense } \\
\text { molecule that inhibits translation of an mRNA that encodes a } \\
\text { BKI1-type polypeptide. }\end{array}$ \\
\hline
\end{tabular}

WO 2009002440 A nucleic acid molecule that downregulates expression of an epidermal growth factor receptor (EGFR) gene via RNA interference; useful for preparing a composition for treating or preventing EGFR-expressing cancer.

WO 2008155918 A method of promoting or inhibiting activity of hypoxiainducible factor- $1 \alpha$ (HIF-1 $\alpha$ ), involving increasing or reducing the interaction of intracellular inhibitor of factor inhibiting HIF-1 (iFIH) protein and factor inhibiting HIF-1 (FIH-1) protein, or increasing or reducing the interaction of intracellular membrane type 1-matrix metalloproteinase-cytoplasmic tail binding protein (MT1-MMP-CP) and FIH-1 protein. The interaction of $\mathrm{iFIH}-1$ and $\mathrm{FIH}-1$ protein is reduced by decreasing the expression of $\mathrm{iFIH}-1$ protein by RNA interference.

US 20080311081, An invasive bacterium comprising small interfering RNA that WO 2008156702, interferes with the mRNA of human papilloma virus (HPV) WO 2008156661 oncogenes; useful for treating or preventing a viral disease or disorder-e.g., HPV infection.

WO 2008152131 A new RNA interference agent comprising sense strand; useful for treating a human subject afflicted with cystic fibrosis or Liddle syndrome, and for treating and/or preventing hypertension and/or renal insufficiency in a human subject.

JP 2008301812 A kit comprising a vector containing a promoter derived from phage used for producing double-stranded RNA having an RNA interference effect in lactic acid bacteria. The lactic acid bacteria are useful in compositions for killing intestinal parasites and treating enteric diseases-e.g., Caenorhabditis and Ascaris.

WO 2008148304, An HIV-targeted RNA interference target sequence; useful for CN 101314775 treating HIV infection.

CN 101246169 A diagnostic reagent for oral squamous cell carcinoma comprising a reagent capable of detecting the expression level of RACK 1 protein and its mRNA content; useful for preparing a kit or biochip for oral mucosa carcinoma. The drug comprises an RNA interference molecule of RACK1 protein.

JP 2008167739 A novel modified double-stranded RNA having RNA interference activity, comprising sense strand RNA having a complementary base sequence to a target gene and an antisense strand RNA for suppressing expression of the target gene.

\section{Salk Institute for}

Assignee

Biological Sciences

(La Jolla, CA, USA)
Priority

application date Publication date

Chory J, Wang X 1/10/2007 1/8/2009

Liu Y, Xie FY, Yang X Liu Y, Xie FY, Yang $X$

$6 / 22 / 2007$

$12 / 31 / 2008$

University of Tokyo Sakamoto T,

$6 / 20 / 2007$

$12 / 24 / 2008$

(Tokyo) Seiki M
Cequent

Pharmaceuticals

(Cambridge, MA,

USA); Fruehauf J,

Laroux FS, Sauer NJ,

Vaze MB, Beth Israe

Deaconess Medical

Center (Boston)

Novartis (Basel, Switzerland)

Okayama University (Japan)

$\begin{array}{ll}\text { Fruehauf J, } \quad 6 / 15 / 2007 & 12 / 18 / 2008, \\ \text { Laroux FS, } & 12 / 24 / 2008, \\ \text { Sauer NJ, Vaze MB, } & 12 / 24 / 2008\end{array}$

Li C

Danahay $\mathrm{HL}$,

$6 / 15 / 2007$

$12 / 18 / 2008$

Geick A

Hickman E,

Tan P, van Heeke G,

Vornlocher $\mathrm{H}$

Otsuki T,

Shishido M

$5 / 10 / 2007$

$12 / 18 / 2008$

Xiamen University

(Xiamen, China);

Cheng T, Miao J,

$5 / 31 / 2007$

$12 / 11 / 2008$

(Haikou, China)

University of Sichuan Ceng X, Chen Q,

(China)

$5 / 23 / 2007$

National Institute of Bakalova R, Xia N, Zhang J,

Huang $C$, Wang Z

$8 / 20 / 2008$

$6 / 14 / 2006$

$7 / 24 / 2008$

$12 / 3 / 2008$

Kubo T, Oba H, Zhelev Z

Science and

Technology (Tokyo)

Source: Thomson Scientific Search Service. The status of each application is slightly different from country to country. For further details, contact Thomson Scientific, 1800 Diagonal Road, Suite 250, Alexandria, Virginia 22314, USA. Tel: 1 (800) 337-9368 (http://www.thomson.com/scientific). 